\title{
The discussion on the progressive education of children and adolescents
}

\author{
Li Yao \\ School of Electromechanical \& Architectural Engineering, Jianghan University, Wuhan, Hubei, China
}

Keywords: education of setbacks, gradual influence, inspiration

\begin{abstract}
The methods of education for children and adolescents have been discussed in this paper, which ought to be the essential knowledge for parents and teachers to carry out children's education of setbacks, gradual influence, inspiration and the sense of shame. It is believed that children's education should be based on the ability of cognition and acceptance to avoid putting the cart before the horse. The parents and teachers who have the greatest impact on their children are likely to leave children indelible impressions, so it is best to encourage them instead of preaching. In a bid to nurture a child's self-esteem, do not easily come to conclusions for the things they have done but to help them analyze whether they are good or bad and right or not.
\end{abstract}

\section{Introduction}

How to educate children is a problem that every parent and every teacher need to face, and they have been rather bemused by children. Young people will meet various problems when they are growing up. It is good for their growth to solve these problems. The following is to talk about the problems and methods of children's education in the course of their growth.

\section{Methods for children's education}

\subsection{Understanding children's psychology.}

It is necessary for parents and teachers to learn children's psychology and apply it properly. To educate children, the most important thing is to understand their inner hearts. Unfortunately, some parents and teachers have little knowledge of children's psychology in a certain way that they are not as good as the soothsayer. Why so many people believe the soothsayer? Because the fortune teller has three principles which include boasting young people, scolding the middle age, and comforting the old age. They know, from the point of view of human nature, almost every middle-aged person does not satisfy with his/her own destiny ${ }^{[1]}$. If the fortune teller says a person is not good, this man/woman would unconsciously believe in the soothsayer and regard the soothsayer as 'God'. For the elder, generally, their health is not good, especially for the elder with heart diseases or hypertension. So the fortune tellers tend to comfort them. As for adolescents, they have not clear orientation for their future career and life currently, and possess the strongest plasticity. The fortune tellers often give them more encouragement, which is beneficial to the growth of young people. So, the parents and teachers had better understand children's psychology before they educate them.

\subsection{Giving setback education.}

Setback education is to let the educated suffer setbacks in educating so as to stimulate their potential, and make them master the knowledge. When children grow up, few of them have had the opportunity to take setback education. Teenagers are more vulnerable than adults, and are not prepared to suffer any failures ${ }^{[2]}$. Even if they are willing to face the failure, the parents themselves will often help handle it. This way of education is not good for the growth of children. It is often reported that some college students easily tend to commit suicide, in addition to psychological factors, another important reason is that they cannot withstand setbacks. However, the overwhelming majority of people in the world will experience setbacks in their lives. This is why setback education is regarded as vital. 
Through a certain setback, it is beneficial for children to form their strong will. Teenagers' behaviors are always casual. They do not consider what their behaviors will result in. So based on the new educational concept, you should give children more setback educations, and children themselves can climb up where they have fallen. The more precious experiences they have, the stronger will and higher ability they will require. Life is to experience countless difficulties and hardships. In order to make them strong and independent, it is necessary to let children adapt themselves to such training from an early age. Parents and teachers should pay attention to helping children gain a successful experience of overcoming difficulties, in order to improve 'self-efficacy' and self-confidence. Children should realize that it is common for a person to encounter a great many setbacks in his whole life, but the key point lies in how you see and treat it correctly. Only with the courage to work hard can you overcome the difficulties and defeat the setbacks. In addition, when children make great efforts to achieve some achievements, they need to be praised and know their abilities to face new difficulties more confidently. The setbacks which people experienced can be taken as a kind of wealth, and it is these experiences that make them survive in this world.

It has been estimated that about $30 \%$ of the primary and middle school students in our country are suffering a psychological disorder, and have not been educated by the setbacks that they should experience during their childhood. Faced with setbacks, children often show more negative emotions, so it is good for us to make children experience a few hardships and realize the truth of life. It is really necessary to cultivate their hardworking spirit, independence, and the courage to cope with difficulties and psychological endurance. Setback education begins with a small setback, not a big setback at first, otherwise, it is beyond their enduring capability. If children fail several times to overcome the difficulties, they should be given specific helps in time.

\subsection{Performing imperceptible influence.}

Imperceptible influence refers to a person whose thoughts and characters are unconsciously infected and influenced. Children in the family are influenced by their parents from birth, and there are a great many words and behaviors, that is, they learn from parents, for parents are the earliest teachers of children. So parents should set an example for their children. Mental state and ideology of teenagers are not yet stereotyped, and their characters and habits are, to a large extent, influenced by their parents. Children living in a clean and tidy environment naturally stay in a calm mood and easily control their temperament. Also, those living in a civilized and ethical interpersonal environment naturally remain positive. Children will subconsciously learn from those closest ${ }^{\text {[3] }}$. Therefore, children's knowledge, recognition, and outlook on life can develop so long as parents play an exemplary role and believe that example is better than precept. This is the effect of imperceptible influence that parents perform for children.

\subsection{Encouraging and Stimulating.}

Children need more encouragement to make them increasingly confident to work and study. Appreciation and motivation are one of the most effective ways to promote children's progress. Compliments on the strengths and achievements of a child can satisfy every child's desire to be valued by parents and teachers. Parents and teachers should carefully observe every child's words and deeds to find out children's merits, and to make sure that children have a good sense of themselves, so that self-motivation will emerge. Many parents and teachers always prefer to use critical tone to educate their children, which is not good for children. In fact, everyone wishes to listen to good things, and likes to listen to be praised. This is true for adults, especially for children. Let children try some things, and when they have made a little progress, it is necessary to continue to encourage them so that children can easily break through their own shortcomings. While children suffer their own shortcomings, parents should adjust their children's mentality in time, let children look at themselves in an all-round way, and recognize their own strengths. By doing so, children can recover quickly from the sufferings and not be immersed in negative comments, which helps children to form self-motivation. 


\subsection{Helping children set goals.}

When children growing up, parents should help them set short-term and long-term goals. It is necessary to set clear goals and put them into action. For example, if a child has a problem with his English pronunciation, he can set himself a goal to read each phonetic alphabet correctly. Their conscious effort to pronounce each phonetic sign is the first step towards self-motivation. However, when setting this goal, attention should be paid to its implement ability. If children set an unrealistic goal, the goal will not only fail, but decrease their enthusiasm and lose self-confidence. If you let a child who failed a lot in his study get grades at 90 or more, obviously, it is unrealistic, even if he tries hard to be able to reach the goal immediately. Gradually, he may abandon himself. Therefore, in setting goals, the conditions of children should come first and it is best to set those goals that are easy to achieve, then gradually increase the difficulty of teaching target. You should set a fixed time for every target of children, and ask them to reach the target before the deadline. With the limit of time, children would feel urgent. Otherwise, the target will become an empty promise without actions. Self-motivating is to make children determine the goal and inspire them to achieve the goal. However, most children lack of self-control, so they can only remain passionate in times of feeling interested.

Parents should let children have a sense of urgency when teaching them how to motivate themselves. Reading targets loudly could be a pretty good habit. In reading targets, children will strengthen the comprehension of what they should do. Meantime, you also let them know that the more you pay, the more you will be rewarded. For example, when they want to reconstruct a model, you could make them imagine what it should look like before they begin, and how many efforts should be paid to make it as it is. Setting a fit time limit is necessary, otherwise, children will feel the target is too far to reach and pay little energy on it. Of course, no one could have no failures in life. the best way to educate children is to teach them how to encourage and applaud for themselves. Positive psychological suggestions will give them the energy to overcome difficulties and help them be a fighter. You should also know it is a long and painstaking process which requires persistent efforts of parents.

\subsection{Educating by proper criticism}

Nobody could be perfect. When teenagers show bad behaviors, it is necessary for parents or teachers to criticize them, but proper methods yield twice the result with half the effort, which include respecting the personality of young people, taking care of their self-esteem, and communicating equally with them, and telling them the facts and reasons. In the same time, the parents ought to have an agreeable altitude. The purpose of critical education is to make children get the point of problems. Sometimes they do not follow you, but they understand clearly what is said. Remember not to satirize them, beat them or even drive them out. Give them some constructive suggestions could be better. When children could not accept it ance, you need to give them some space and time to think about it. Then, a short time later, talk to them again.

\subsection{Supervising children's behaviors and habits}

Children are lack of the ability to judge many objective things, so you need supervise them to carry on their goals. Playing is human nature, especially for teenagers. When the teenagers enjoy themselves, they will forget what they need to do, such as doing homework. Parents or teachers should remind or urge children to study and do what they are required to do. There are two main aspects of the supervision. One is the supervision of their study. The main task of teenagers is to study and complete the schoolwork. What you need do is to urge children to preview, listen carefully in the class, assist them to do their homework, and review and summarize what they have learned. They can also study other subjects ${ }^{[4]}$ which are completed in extracurricular studies, such as piano, martial arts, swimming, running, and other kinds of extracurricular books. The other one is the supervision of their behaviors and habits ${ }^{[5]}$. The first thing is to make them responsible for their own behaviors. Only being responsible for their own behaviors could children know what self-supervision talks about. After realizing this, they will consider the consequences unconsciously 
when working on what they do.

\subsection{Reinforcing safety education}

It is a normal thing for people to cross the road. But it could be dangerous when you pay little attention to your safety. It has been assumed that drivers dare not hit you, but everyone could have the moment lacking of concentration. If a car hits you, you will be injured and even lose your life. It is not a good idea to take the risk of giving your life to others. When doing so, your life is not far from death. It is quite important to educate children to take full control of their own lives themselves.

\section{Conclusion}

The above methods can be carried out by parents and teachers and it is believed that children's education will be greatly improved.

\section{References}

[1] Gui Wanchun. All things in their being are good for something. Anhui Art Press, 2013:114-115.

[2] Li Fengtang. Life Education: guiding the healthy growth of teenagers. Journal of Tianjin Academy of Educational Science, 2017(06):28-31.

[3] Gao Yuanqiong. Value education of the youth. Journal of Lvliang Education College, 2017, 34 (03):4-5.

[4] Chun Zaiqing. On the cultivation of Youth lifelong physical Education by Family Physical Education. Science \& Technology Information, 2017,15(33):164-166.

[5] Zhang Qin, Chen Yixin. Cai Yuanpei's thoughts on Modern Children's Education and Modern Family Education. Journal of Shanghai Normal University (Philosophy \& Social Sciences Edition), 2016(2):136-143. 